\title{
Canada needs more-aggressive problem-gambling policies, say researchers
}

A 11 the fancy trappings in casinos - the illuminated fountains spouting in rhythm to orchestral music, the elaborate replicas of renowned monuments, the neon signs blinking like post-blackout clock radios — are made possible by one thing: losing. Lots and lots of losing.

In Canada, where provincial governments run games of chance, losing also pays for less gaudy items: highways, schools, health care, etc. But who, exactly, is doing all the losing? Who's pumping millions of dollars into slot machines and lotteries to help provinces meet their budgets?

Turns out that a large portion of those doing the losing, up to half in some areas, are people with pathological gambling problems. This comes as little surprise to researchers studying gambling, who suggest that provinces are reluctant to make aggressive policies to reduce problem gambling because it would cut into their revenues.

"They're the promoter, the operator, the regulator and the main beneficiary. That's a horrible conflict-of-interest situation," says Garry Smith, who specializes in gambling research at the University of Alberta in Edmonton. "Social responsibility should trump revenue. You don't want to prey on your vulnerable citizens. Are we willing to trade off on suicides, bankruptcies and other social costs for the money?"

In a new paper in Addiction about the nature and scope of gambling in Canada, Smith notes that provinces expanded gambling quickly over the past four decades, with little public con- sultation and scant concern for negative social or health consequences (Addiction 2013 doi: 10.1111/add.12210).

concerns: "Despite mounting evidence showing that problem gamblers contribute a disproportionate share of total gambling revenues, government social responsibility initiatives have not rectified the problem."

This stands in stark contrast to efforts to reduce the harm caused by products such as tobacco and alcohol, note researchers. Provinces have instituted policies to curb the social and health costs of consuming these substances by limiting availability, increasing prices and controlling how they are served.

"We have nothing really analogous in gambling. All the efforts thus far have focused on education admonishing people to gamble responsibly, putting the odds on tickets or raising awareness about a hotline," says Robert Williams, a research coordinator for the Alberta Gambling Research Institute, based in Edmonton. "There are no policy measures to constrain gambling."

This does indeed appear to be the case, if email responses from provincial gambling regulators to CMAJ inquiries are

Canada is now home to more than 70 casinos, 30000 lottery outlets and 96000 electronic gaming machines. In 2010/2011, gross revenues from gambling totalled $\$ 13.9$ billion. On average, Canadians each lose $\$ 568$ a year gambling, the fourth highest rate in the world.

Gambling is treated as a "profitdriven business enterprise," Smith notes in his paper, and associated problems such as addiction, suicide and pathological gambling are treated as minor any indication. When asked to describe their problem-gambling policies, many regulators used similar words and phrases: helpline, media campaign, raising awareness, counselling, promote responsible gambling, etc.

Initiatives by the Alberta Gaming and Liquor Commission, for example, include a responsible-gambling social marketing campaign, responsiblegambling information centres, efforts to discourage youth from gambling and education for industry staff about 
problem gambling. "These programs help patrons assess their play behaviour and, where needed, take appropriate actions to address any concerns they may have about those behaviours," Kelly Holmes, director of program services for social responsibility and licensing/compliance, writes in an email.

The government of Saskatchewan also highlighted efforts to raise awareness without mentioning any restrictive policies. "We think we do a good job in providing problem-gambling prevention services," Heather Murray, director of research, evaluation and central support for the health ministry's community care branch, writes in an email. "We have included the helpline number in the most recent media campaigns to direct individuals to available services. Our latest media campaign also addresses the feeling of isolation that many problem gamblers feel and shows them where they can go for help.'

In British Columbia, the province provides "GameSense" advisors in casinos, who answer questions about how games works, winning odds and gambling myths. And, like other provinces, it has a helpline. "The B.C. government's Responsible Gambling Strategy effectively addresses problem gambling through treatment and prevention services such as a 24-hour multilingual helpline and free, no-waitlist clinical counselling. Last year, the helpline received more than 4000 calls," a spokesperson (who requested anonymity) for the Ministry Responsible for Gaming, writes in an email.

The problem with these types of services, though, is that only a small percentage of problem gamblers - in the neighbourhood of $10 \%-15 \%$ - will access them of their own accord. What's needed, say researchers, are policies that will reduce the amount of money problem gamblers spend, whether they like it or not. "Purveyors of gambling say they can't babysit people who are responsible adults. But people with addictions aren't responsible adults. They are out of control. They do need some kind of intervention," says Smith. "There are things you can do that are much more rigorous and are reasonable, and I don't think most gamblers who don't have a problem would object."

There are, in fact, many aggressive policies — ones that don't wait for the lives of people with addictions to become so desperate that they seek help - that have been shown to reduce problem-gambling rates, Williams and colleagues noted in a comprehensive review of best practices (www.uleth .ca/dspace/handle/10133/3121). These include reducing the number of venues, eliminating the highest-risk forms of gambling, constraining maximum bet amounts, requiring gamblers to precommit to daily expenditure limits, asking all patrons for identification to enforce self-exclusion lists and restricting access to alcohol and automated banking machines in casinos.

European countries tend to have far stricter policies, notes Williams, and, as a result, their problem-gambling rates are only a fraction of those in Canada. Some practices allowed by provincial governments, such as providing gamblers with rewards if they spend more, may actually be contributing to problem gambling. "These things don't make any sense," says Williams. "Canadians would never accept being rewarded for alcohol consumption, but we do that for gambling."

Because provincial policies are limited, problem gamblers continue to contribute a disproportionate amount to gaming revenues. In a 2004 study in Analyses of Social Issues and Public Policy, based on data from eight provinces, Williams estimated that $4.2 \%$ of Canadians were problem gamblers, yet they accounted for $23.1 \%$ of gambling revenue (Anal Soc Issues Public Policy 2004;4:33-45).

A 2011 report for the Alberta Gambling Research Institute prepared by Williams and colleagues indicated that problem gamblers are responsible for about $50 \%$ of gambling expenditures in Alberta, and account for an even higher rate of money swallowed by slot machines and video lottery terminals. (http://research.uleth.ca/seiga/seiga_fin al_report.pdf). Since 2008, gambling revenues have made up between $4 \%$ and $5 \%$ of total government revenues, states the report, which also suggests that roughly $10 \%$ of suicide attempts in Alberta are gambling-related.

The situation in Ontario isn't much better. A 2007 study in Canadian Public Policy, with data from 364 people who kept four-week diaries, found that $36 \%$ of revenues in Ontario came from problem gamblers (Can Pub Policy 2007;33:367-88). "Thirty-six percent of revenues derived from problem gambling would be a problematic figure for private industry, let alone a government-run operation whose purpose is to serve the people, not to exploit the people," the paper states.

Reducing problem gambling might reduce revenues, but it would do wonders to improve the lives of not only those addicted to gambling, but also those of employees in casinos and other gambling venues, suggests Robert Murray, manager of the Problem Gambling Project at the Centre for Addiction and Mental Health in Toronto, Ontario.

"That is probably the most difficult aspect of working in this industry, having family members pounding on the door and yelling 'Get my husband out of there,", says Murray. "Everyone wants to feel that they work in an environment that takes care of their customers."

Though there is still much room for progress in reducing problem gambling, the industry does appear more open to intervening now than in the past, says Murray. The Centre for Addiction and Mental Health has worked with people employed in the gambling industry to help them identify when and how to intervene.

"We are not trying to train them to be clinicians or to diagnose a gambling problem, but there are hundreds of thousands of people walking through the doors of casinos every day, and those employees are going to be dealing with problems whether or not they have training," says Murray. "We equip them with certain basic communication skills and an understanding of how to positively engage people, and how to link the customer to available resources should they need that." - Roger Collier, CMAJ

CMAJ 2013. DOI:10.1503/cmaj.109-4503 